\title{
SOLOR IRRADIATION ANALYSIS USING PRESCRIPTIVE ANALYSIS
}

\author{
Pawan Kumar Singh \\ Department of IT \\ SRM Institute of Science and Technology, \\ Ghaziabad, Uttar Pradesh, India
}

\author{
Raghav Sobti \\ Department of IT \\ SRM Institute of Science and Technology, \\ Ghaziabad, Uttar Pradesh, India
}

\begin{abstract}
Solar Irradiation Analysis using Prescriptive Analysis is a design for an ideal solution, built on the user's needs to analyze Solar Power Plants. It helps in delivering flawless operations on the data provided from the power plants, and predicts volatility in performance by providing probable reason of up-gradation/degradation in efficiency. It focuses on the idea of Sustainable Energy Resources as the future needs to be more Eco-friendly. Solar Irradiation Analysis using Prescriptive Analysis is the combination of hardware (which includes solar panels, invertors, connections, and other devices) and an Intuitive software (Coded in Python, using Data Analytics Techniques). Data Analytics which includes Descriptive Analysis, Predictive Analysis and Prescriptive Analysis is secure, reliable, and compatible with all kinds of data. The results are generated in the form of graphs and charts which can be useful in the long term for the future studies based on Solar Irradiation, and in the short term they provided better energy generation of Users.
\end{abstract}

Keywords - Solar Irradiation, Ambient Temperature, Solar Data Analyzer

\section{INTRODUCTION}

SOLAR DATA ANALYSER is a standalone software made on Python 3.7. It is used for Big Data Analytics on Solar Panel Energy Generation. The Data provided to us was given by a well-known company named e-SENZ pvt ltd. which is a Solar based company who provides on-grid systems all over India. Basically the software is dealing with the analysis of the Big Data provided by the on-grid system and show the results according to the customers need. In a general Solar Panel onGrid system the performance can be monitored very easily but if there is any degradation in the efficiency then finding the exact reason of the problem is very difficult for the technician and it's also very time consuming. To reduce the time and for finding the exact reason of the problem, this software analyses the data and concludes the reason of problem with an appropriate solution.

\author{
Akhileshwar Nanduri \\ Department of IT \\ SRM Institute of Science and Technology, \\ Ghaziabad, Uttar Pradesh, India \\ Dr. Anna Alphy \\ Department of IT \\ SRM Institute of Science and Technology \\ Ghaziabad, Uttar Pradesh, India
}

\section{PROPOSED ALGORITHM}

Solar Tech Algorithm -

Researching about Solar Irradiation and the factors affecting them, we found that the Solar Irradiation is being fluctuated according to (BRI, 1984). And there should be one constant factor available to normalize the variation of Solar Irradiation. We named algorithm as Solar Tech Algorithm.

Then according to (Gago et al., 2010) we found that there is one inter relation between Solar Irradiation (IRR) and Ambient (Amb) Temperature, which made this possible to perform z-test and compare both the years data to conclude the result.

The Algorithm which we made has 3 phases:

1 Performing Z-test separately on Solar Irradiation and Ambient Temperature which will help us decide the Alternative Hypothesis is greater than Null Hypothesis.

2 After determining the Null and Alternative Hypothesis we will calculate energy with a relation given by (Gago et al.,2010).

3 After calculating the energies produced by both the years we will compare the variation difference in mean values of energies within 5 percent in range.

If the value is greater than 5 percent then the efficiency is degrading because of Weather Conditional Changes. Then the further conclusions can be given on the possibility of shading effect and dust layer over the panels, which require servicing and maintenance.

For technical problem detection we analyze the factor of Module Temperature provided in the Data-Set which should be under 2540 degree Celsius.

If the max value of module temperature is greater than this range then there is a possibility of overheating and short circuit. If the module is overheating then definitely there is a possibility of technical failure which will degrade the efficiency of the system. 


\section{a) Z-Test Calculation Procedure}

For performing Z-Test we need 5 values to calculate i.e.;

1. Mean of Solar Irradiation for both the years.

2. Number of Samples

3. Standard deviation for both the samples.

In Figure $3.1 \bar{X}_{1}$ and $\bar{X}_{2}$ are the means of the two samples, is the hypothesized difference between the population means ( 0 if testing for equal means), $n 1$ and $n 2$ are the sizes of the two samples and $\sigma 1$ and $\sigma 2$ are the standard deviations of the two population.

In the end the value of $\mathrm{z}$ is compared with the $\mathrm{z}$ table value at 0.05 , where it is concluded whether it greater or smaller than Null Hypothesis.

$$
\text { Formula: } z=\frac{\bar{x}_{1}-\bar{x}_{2}-\Delta}{\sqrt{\frac{\sigma_{1}^{2}}{n_{1}}+\frac{\sigma_{2}^{2}}{n_{2}}}}
$$

Fig. 1. Z-Test Formula

\section{b) Energy Calculation}

The formula in Figure3.2 is derived by (Gago et al., 2010) where there is an inter-relationship between Solar Irradiation and Ambient Temperature. Here $\bar{G}$ is Solar Irradiation mean, $K r$ is Empirical Constant with the value of 0.16, Tmax and Tmin is the Ambient Temperatures and $\bar{E}$ is the Energy Mean.

$$
\bar{G}=K_{\mathrm{r}}\left(T_{\max }-T_{\min }\right)^{0.5} \bar{E}
$$

Fig. 2. Energy Calculation Formula

\section{EXPERIMENT AND RESULT}

- To corroborate that the system will work duly as we wanted it to be, first test the ac- curacy of the analysis using our algorithm. We obligate to see the precision of methodology which we are using in Weather Conditional Analysis.

- Testing under Technical Failures allows for the analysis and consistency of varied situations and accuracy is then $\mathrm{c}$ calculated.

- Also, alongside accuracy we'll calculate time interval of the system under Technical Failures with the goal to analyze that under what proportion of time our analysis will detect failures.
- For testing, we'll test the working of our analysis on factors which can have different effects like shading effect, Physical damages etc. A tabular documentation is constructed as a Dataset so that analysis is made. There in table, for each factor, the micro-controller successfully detected and not detected for that factors are going to be documented alongside time interval of every 5 minute.

- In the end, the graphs are plotted and prescription is described to see the final results.

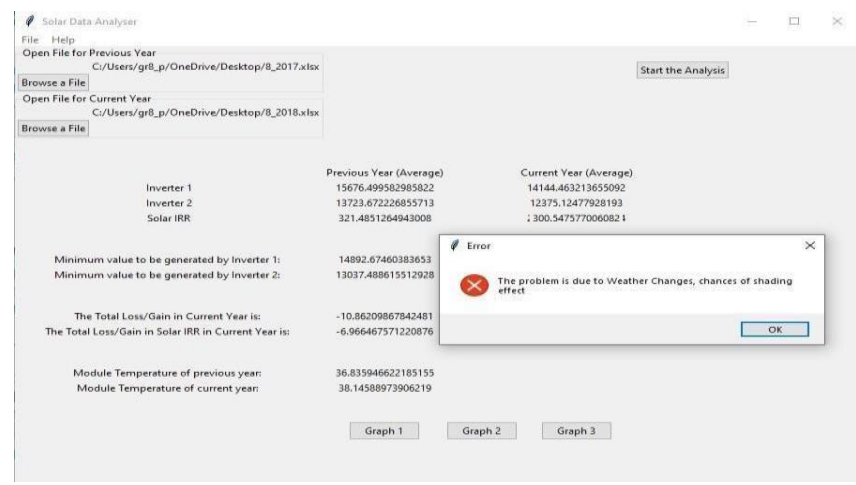

Figure 3. Perfect Condition

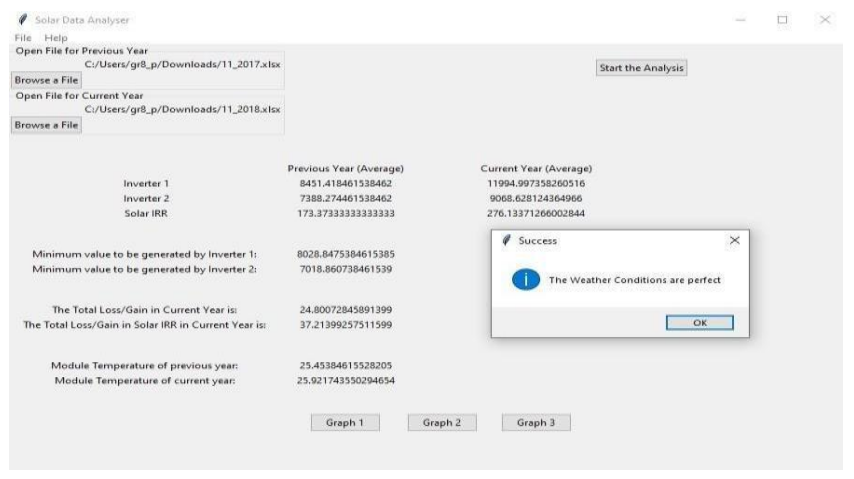

Figure 4. Error Conditions

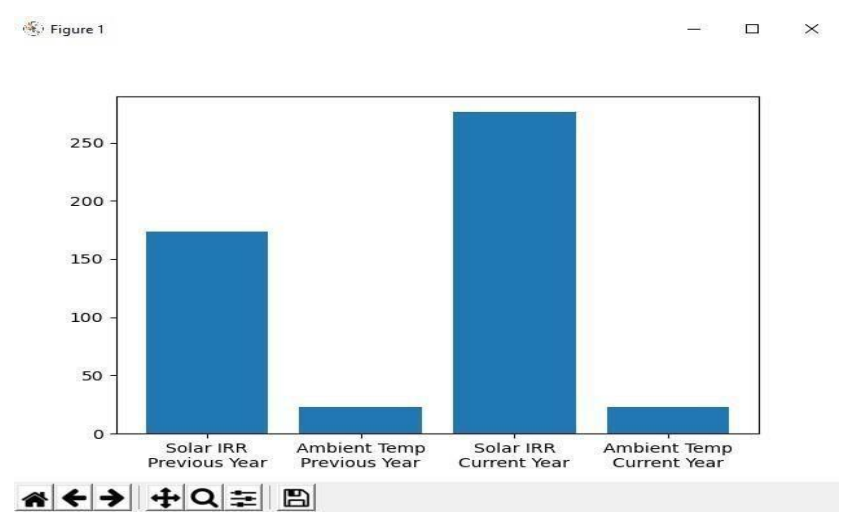

Figure 5. Solar Irradiation and Ambient Temperature Graph 


\begin{tabular}{|c|c|c|c|c|c|c|}
\hline $\begin{array}{c}\text { Coun } \\
\text { ter }\end{array}$ & $\begin{array}{c}\text { Date and } \\
\text { Time }\end{array}$ & $\begin{array}{c}\text { Inverte } \\
\text { r-1 }\end{array}$ & $\begin{array}{c}\text { Inverte } \\
\text { r-2 }\end{array}$ & $\begin{array}{c}\text { SOL- } \\
\text { IRR }\end{array}$ & $\begin{array}{c}\text { Amb- } \\
\text { TEMP }\end{array}$ & $\begin{array}{c}\text { Mod- } \\
\text { TEMP }\end{array}$ \\
\hline 1 & $\begin{array}{c}11 / 1 / 2017 \\
0: 01\end{array}$ & $\begin{array}{c}3.30 \mathrm{E} \\
+07\end{array}$ & $\begin{array}{c}2.86 \mathrm{E} \\
+07\end{array}$ & 0 & 20.1 & 15.9 \\
\hline 2 & $\begin{array}{c}11 / 1 / 2017 \\
1: 03\end{array}$ & $\begin{array}{c}3.30 \mathrm{E} \\
+07\end{array}$ & $\begin{array}{c}2.86 \mathrm{E} \\
+07\end{array}$ & 0 & 19.4 & 15.6 \\
\hline 3 & $\begin{array}{c}11 / 1 / 2017 \\
2: 03\end{array}$ & $\begin{array}{c}3.30 \mathrm{E} \\
+07\end{array}$ & $\begin{array}{c}2.86 \mathrm{E} \\
+07\end{array}$ & 0 & 18.7 & 15.6 \\
\hline 4 & $\begin{array}{c}11 / 1 / 2017 \\
3: 05\end{array}$ & $\begin{array}{c}3.30 \mathrm{E} \\
+07\end{array}$ & $\begin{array}{c}2.86 \mathrm{E} \\
+07\end{array}$ & 0 & 19.4 & 15.6 \\
\hline 5 & $\begin{array}{c}11 / 1 / 2017 \\
4: 05\end{array}$ & $\begin{array}{c}3.30 \mathrm{E} \\
+07\end{array}$ & $\begin{array}{c}2.86 \mathrm{E} \\
+07\end{array}$ & 0 & 18.5 & 15.9 \\
\hline 6 & $\begin{array}{c}11 / 1 / 2017 \\
9: 05\end{array}$ & $\begin{array}{c}3.31 \mathrm{E} \\
+07\end{array}$ & $\begin{array}{c}2.86+ \\
07\end{array}$ & 153 & 25.6 & 16.1 \\
\hline 7 & $\begin{array}{c}11 / 1 / 2017 \\
10: 07\end{array}$ & $\begin{array}{c}3.31 \mathrm{E} \\
+07\end{array}$ & $\begin{array}{c}2.86+ \\
07\end{array}$ & 236 & 33.6 & 15.1 \\
\hline 8 & $\begin{array}{c}11 / 1 / 2017 \\
11: 40\end{array}$ & $\begin{array}{c}3.31 \mathrm{E} \\
+07\end{array}$ & $\begin{array}{c}2.86+ \\
07\end{array}$ & 245 & 34.6 & 15.3 \\
\hline 9 & $\begin{array}{c}11 / 1 / 2017 \\
12: 00\end{array}$ & $\begin{array}{c}3.32 \mathrm{E} \\
+07\end{array}$ & $\begin{array}{c}2.87+ \\
07\end{array}$ & 315 & 37.6 & 15.4 \\
\hline 10 & $\begin{array}{c}11 / 1 / 2017 \\
13: 35\end{array}$ & $\begin{array}{c}3.32 \mathrm{E} \\
+07\end{array}$ & $\begin{array}{c}2.87+ \\
07\end{array}$ & 327 & 37.6 & 15.3 \\
\hline 11 & $\begin{array}{c}11 / 1 / 2017 \\
16: 25\end{array}$ & $\begin{array}{c}3.31 \mathrm{E} \\
+07\end{array}$ & $\begin{array}{c}2.86+ \\
07\end{array}$ & 207 & 31.4 & 15.7 \\
\hline 13 & $\begin{array}{c}11 / 1 / 2017 \\
17: 05\end{array}$ & $\begin{array}{c}3.31 \mathrm{E} \\
+07\end{array}$ & $\begin{array}{c}2.86+ \\
07\end{array}$ & 155 & 25.2 & 15.1 \\
\hline $18: 26$ & $\begin{array}{c}3.31 \mathrm{E} \\
+07\end{array}$ & $\begin{array}{c}2.86+ \\
07\end{array}$ & 96 & 18.6 & 15.2 \\
\hline+07 & $\begin{array}{c}2.86+ \\
07\end{array}$ & 0 & 17.6 & 15.7 \\
\hline
\end{tabular}

Table -1 Sample Dataset

\section{CONCLUSION}

The approach used here for SOLAR DATA ANALYTICS decreases the calculation time making results with high accuracy. The outcome which is expected from the project is given with the help of Data Analytics model that is used in the project to analyze the Weather Conditions on the basis of input provided by the User's Solar Data-Set so as to alert any degradation inefficiency during the peak hours, and immediately analyze the reason behind it. Extraction of the probable element finds imperative component positions in the system organize inside a deprecated module info. The data is first parsed in the software and further analyze afterwards. Each data set is calculated for the analysis according to the algorithmic procedure. After that data programmed attach in software in the wake of technical failure programmed spared in graph, and it will get plotted. In the present situation, sustainable energy efficiency enhancer has become the prime concern for everyone. Effort to create a way for Solar Data Analyzer that is usable, rational but effective is done in this project.

\section{ACKNOWLEDGEMENT}

We would like to express our deep gratitude to our guide, professor Dr. Anna Alphy from department of information technology, SRM institute of science and technology for her valuable guidance, consistence encouragement, active abetment, timely help and providing us with excellent environment for doing research

Although the work, in spite of busy schedule, he has been extensively cheerful and amicable support to us for completing the research work.

\section{REFERENCE}

[1] (1984). "On the relationship between incoming solar radiation and daily maximum and minimum temperature." Agricultural and ForestiMeteorology, 31(2), 159-166.

[2] Gago, E., Etxebarria, S., Tham, Y., Aldali, Y., and Muneer, T. (2010). "Inter- relationship between mean-daily irradiation and temperature, and decomposition mod- els for hourly irradiation and temperature." International Journal of Low-Carbon Tech-nologies, 6(1),22-37.

[3] King, D., Kratochvil, J., and Boyson, W. "Measuring solar spectral and angle-of-

Incidence effects on photovoltaic modules and solar irradiance sensors." Conference Record of the Twenty Sixth IEEE Photovoltaic Specialists Conference-1997.

[4] kwang Song, S., Jeong, D.-H., Kim, J., Hwang, M., Gim, J., and Jung, H. (2014). "Research advising system based on prescriptive analytics." Lecture Notes in Electrical Engineering, Springer Berlin Heidelberg,569- 574.

[5] Louche, A., Maurel, M., Simonnot, G., Peri, G., and Iqbal, M. (1987). "Determination of Ångström's turbidity coefficient from direct total solar irradiance measurements." Solar Energy, 38(2), 89 $\neg 96$.

[6] Solanki, S. K., Krivova, N. A., and Haigh, J. D. (2013). "Solar irradiance variability and climate." Annual Review of Astronomy and Astrophysics, 51(1),311-351.

[7] Willson, R.and Mordvinov, A. (2003). "Secular total solar irradiance trend during solar cycles 21-23." Geophysical Research Letters - GEOPHYS RES LETT,30,3-1. 
[8] Louche, A., Maurel, M., Simonnot, G., Peri, G., and Iqbal, M. (1987). “Determination of Ångström's turbidity coefficient from direct total solar irradiance measurements." Solar Energy, 38(2), 89 - 96.

[9] Solanki, S. K., Krivova, N. A., and Haigh, J. D. (2013). "Solar irradiance variability and climate." Annual Review of Astronomy and Astrophysics, 51(1), 311-351.

[10] Willson, R. and Mordvinov, A. (2003). "Secular total solar irradiance trend during solar cycles 21-23." Geophysical Research Letters - GEOPHYS RES LETT, 30, 3-1.

[11] WILLSON, R. C., GULKIS, S., JANSSEN, M., HUDSON, H. S., and CHAPMAN, G. A. (1981). "Observations of solar irradiance variability." 211(4483), 700-702.

[12] WILLSON, R. C., GULKIS, S., JANSSEN, M., HUDSON, H. S., and CHAPMAN,

G. A. (1981). "Observations of solar irradiance variability.” 211(4483), 700-702. 